University of Nebraska - Lincoln

DigitalCommons@University of Nebraska - Lincoln

Faculty Publications: Department of Entomology

Entomology, Department of

$2-1982$

\title{
Selection of Biotype Populations 2 and 3 of Nilaparvata lugens by Exposure to Resistant Rice Varieties
}

\author{
P. K. Pathak \\ International Rice Research Institute \\ E. A. Heinrichs \\ International Rice Research Institute, eheinrichs2@unl.edu
}

Follow this and additional works at: https://digitalcommons.unl.edu/entomologyfacpub

Part of the Agriculture Commons, and the Entomology Commons

Pathak, P. K. and Heinrichs, E. A., "Selection of Biotype Populations 2 and 3 of Nilaparvata lugens by Exposure to Resistant Rice Varieties" (1982). Faculty Publications: Department of Entomology. 840. https://digitalcommons.unl.edu/entomologyfacpub/840

This Article is brought to you for free and open access by the Entomology, Department of at DigitalCommons@University of Nebraska - Lincoln. It has been accepted for inclusion in Faculty Publications: Department of Entomology by an authorized administrator of DigitalCommons@University of Nebraska - Lincoln. 


\title{
Selection of Biotype Populations 2 and 3 of Nilaparvata lugens ${ }^{1}$ by Exposure to Resistant Rice Varieties
}

\author{
P. K. Pathak and E. A. Heinrichs
}

Department of Entomology, International Rice Research Institute, Manila, Philippines

\begin{abstract}
The release of an insect pest-resistant variety and subsequent adaptation of the insect species to that variety through the process of biotype selection has occurred on many cultivated crops. The present study was designed to obtain detailed information on some of the processes involved in the selection of biotypes of Nilaparvata lugens (Stål) on two rice varieties with different major genes for resistance. The N. lugens population selected for the study, which had originally been collected in the field and reared on a susceptible variety for 12 years (ca. 140 generations), initially had a low survival on the resistant rice varieties Mudgo (Bph 1 gene) and ASD7 (bph 2 gene) and high survival on the susceptible variety, Taichung Native 1 (TN1). Monitoring the survival and length of the developmental period for seven generations indicated a progressive increase in the survival and shortening of the nymphal period in each generation on the heretofore resistant varieties until they were similar to those on TN1. The shift in the population to a more virulent biotype was also confirmed by the seedling bulk test. The selected populations reared on Mudgo or ASD7 were not able to kill Mudgo or ASD7, respectively, in the fifth generation but by the eighth generation were able to do so. In addition, adult longevity and fecundity on the resistant varieties increased during the selection process.

Nilaparvata lugens (Stål) is one of the major insect pests of rice and has had a distinct economic effect on rice production in many Asian countries (Dyck and Thomas 1979). It is a monophagous pest, limited to feeding on Oryza sativa and wild rice species. The epidemic of outbreaks of N. lugens in 1972, 1973, and 1974 in several Asian countries including the Philippines stimulated rice scientists to accelerate the development of rice varieties resistant to this pest. Genetic analysis of several rice varieties resulted in identification of two
\end{abstract}


dominant (Bph 1 and Bph 3) and two recessive (bph 2 and bph 4) genes for resistance (Khush 1979). Resistant varieties were released to farmers for commercial cultivation, but the situation became alarming when their resistance became ineffective because of the apparent selection for a virulent biotype of the pest in Indonesia, the Philippines, Solomon Islands, and Vietnam (Khush 1979). The term biotype as used in this paper refers to populations of $N$. lugens which differ in their ability to feed on and destroy varieties with specific major genes for resistance. Studies of the possible occurrence of $N$. lugens biotypes resulted in identification of biotypes 1,2, and 3 (Anonymous 1976). Biotype 1, the general field population or wild strain in the Philippines, can only destroy varieties having no genes for resistance. Biotype 2 destroys varieties such as Mudgo with the Bph 1 gene (resistant to biotypes 1 and 3), whereas biotype 3 can infest varieties such as ASD7 having the bph 2 gene for resistance (resistant to biotype 1 and 2) (Pathak 1977). Biotype 2 became abundant in the Philippines and Indonesia after IR26 (Bph 1 gene) had been widely grown for about 3 years. The occurrence of biotype 3 has not yet been reported from the field, where varieties such as IR36 having the bph 2 gene have been grown for about 3 years. Biotype 3 is, however, being cultured in the greenhouse on ASD7, which has the same major gene for resistance (Paguia et al. 1980).

Biotype selection has been one of the major problems encountered in breeding for varietal resistance. Most biotypes or variants do not arise de novo because of the cultivation of resistant varieties but are usually present in the population at very low frequencies and are likely to increase with continuous planting of resistant varieties (Gallun et al. 1975). Laboratory studies conducted in Japan (Kaneda and Kisimoto 1979) have shown that the exposure of $N$. lugens to resistant varieties resulted in an increase in the preference of the insect for the resistant variety in successive generations.

The most striking examples of biotypes are well documented in Hessian fly (Gallun et al. 1975), aphids (Eastop 1973), and host races in the genus Rhagoletis (Bush 1969). Hostspecific races have been considered as transient stages for speciation in herbivorous insects. Understanding of the processes involved in host plant adaptation also provides direction for the varietal resistance breeding program. Thus, studies were conducted in the laboratory to determine how samples of a single interbreeding population of $N$. lugens would respond when reared on resistant rice varieties carrying different genes for resistance.

\section{Materials and Methods}

Nilaparvata lugens biotype 1 ( descendants of a wild strain collected before resistant varieties were released to farmers) maintained on the susceptible variety Taichung Native 1 (TN1) for 12 years (ca. 140 generations) in the greenhouse at the International Rice Research Institute (IRRI) was used for the present studies. The mean population size during the 12 years was ca. 50,000 with the smallest population being ca. 10,000.

Unless otherwise mentioned, all the experiments were conducted at $27 \pm 1^{\circ} \mathrm{C}, 65$ to $80 \%$ $\mathrm{RH}$, and 12-h photophase and were replicated 3 to 10 times, using from 1 to 30 insects per replicate, depending on the nature of experiment. N. lugens biotype 1-resistant rice varieties Mudgo (Bph 1 gene) and ASD7 (bph 2 gene) and a susceptible variety TN1 (no gene for resistance) were used in all the tests. 


\section{Variability Test}

In a preliminary study, the variability of the population was determined by testing the survival of the progenies (colonies) of 10 different pairs from the biotype 1 culture separately on 30-day-old Mudgo, ASD7, and TN1 plants. Ten newly emerged 1st-instar nymphs per replicate were caged on potted test plants by using cylindrical mylar film cages. Each treatment was replicated eight times. The percentage of insect survival was recorded 12 days after infestation, the time at which there was no longer any survival in a few of the colonies.

\section{Growth and Development}

Adaptation of N. lugens to the two resistant indica rice varieties, Mudgo and ASD7, was tested by using the scheme illustrated in Figure 1. Growth of newly hatched nymphs on the resistant varieties was determined in respect to (I) insect survival at 13 days after infestation, (II) percentage of nymphs becoming adults, and (III) development period in days from 1st-instar nymph to adult emergence in each generation. Data in II and III were not obtained for the first three generations because there was low survival and it was necessary to transfer the 4th- and 5th-instar nymphs back to TN1 to maintain the colony as indicated in Figure 1. However, beginning with the fourth generation, insects were maintained continuously on the resistant varieties because the colonies had become sufficiently adapted. Weight of the newly emerged adults was recorded only in the seventh generation. Ten insects were used per replication, and each treatment was replicated 10 times.

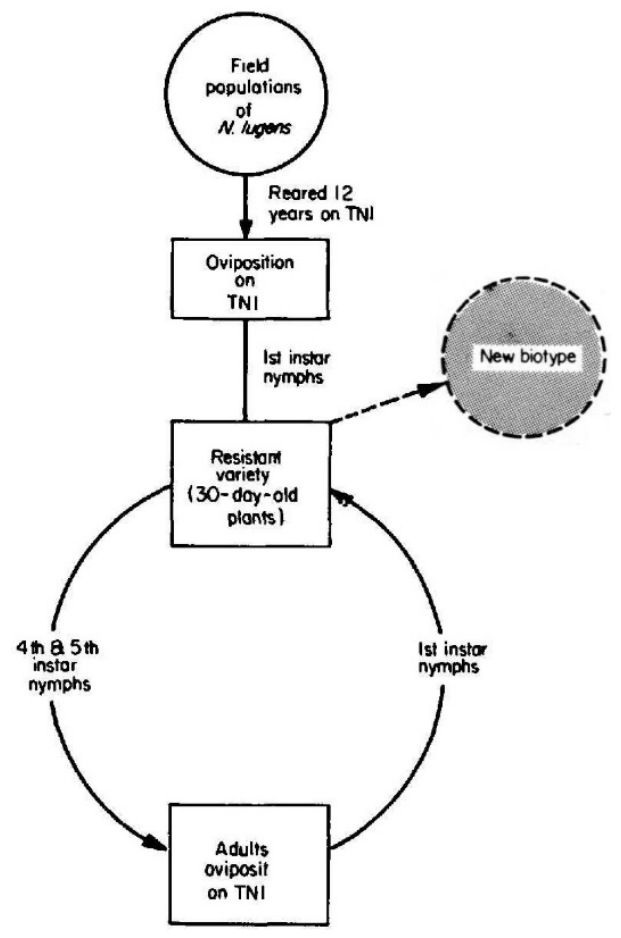

Figure 1. Scheme used to select biotypes on resistant rice varieties. 


\section{Adult Longevity and Fecundity}

The newly emerged males and females of the ninth generation were caged in pairs on 15to 20-day-old plants of the three varieties, and the period of their longevity was recorded.

The preoviposition period and number of eggs produced by a female during its lifetime were recorded. Single pairs of newly emerged adults from the ninth generation were enclosed in a large test tube $(17$ by $3 \mathrm{~cm}$ ) along with 15 - to 20 -day-old test plants (one plant per test tube). Young plants which could easily be removed from the nursery bed were used because of the necessity to examine and thus replace plants daily. Infested plants were examined for eggs by examining the dissected leaf sheath tissue under a binocular microscope.

In both the longevity and fecundity experiment, each replicate consisted of one pair of $N$. lugens on a plant of one variety. Each variety was replicated four times.

\section{Seedling Bulk Test and Population Growth}

To test the virulence of the parent $N$. lugens population and subsequent populations on Mudgo and ASD7, both varieties and TN 1 were sown in a seedbox ( 20 by 20 by $7 \mathrm{~cm}$ ) with three replications. Seven days after sowing seeds, when plants were at the second to third leaf stage, each seedling was infested with ca. 10 1st- and 2nd-instar nymphs. When all the TN1 plants were killed, the damage grades of Mudgo and ASD7 were recorded as based on the standard evaluation system (Pathak and Saxena 1980). Based on the damage grades, treatments were rated as susceptible (S) or resistant (R).

Ability of the selected populations to reproduce and cause mortality of the plants was studied by releasing two pairs of newly emerged adults on 30-day-old test plants (three hills per pot) growing within a cylindrical mylar film cage $(13$ by $90 \mathrm{~cm})$. Plant damage ratings were based on symptoms as given by Pathak and Saxena (1980).

Treatments with all plants killed before 40 days after infestation (DAI) were graded, and the DAI was recorded. Others were graded at $40 \mathrm{DAI}$ when the test was terminated. Insect counts were not taken.

\section{Results}

\section{Variability Test}

Survival of the progenies of different pairs of $N$. lugens biotype 1 indicated the variation in the population. Survival of insects varied from 0 to $56 \%$ on Mudgo and from 8 to $60 \%$ on ASD7 (Table 1). Survival on TN1 was $58 \%$ or more in all colonies. 
Table 1. Variation in survival of the progeny of N. lugens biotype 1 on three rice varieties at 12 days after caging

\begin{tabular}{cccc}
\hline & \multicolumn{3}{c}{ \% Survival $( \pm$ SD) on: } \\
\cline { 2 - 4 } Colony no. $^{a}$ & TN1 & Mudgo & ASD7 \\
\hline 1 & $87 \pm 1.12$ & $0 \pm 0.00$ & $18 \pm 1.10$ \\
2 & $75 \pm 0.63$ & $0 \pm 0.00$ & $40 \pm 1.66$ \\
3 & $80 \pm 1.05$ & $56 \pm 2.14$ & $60 \pm 1.87$ \\
4 & $68 \pm 2.24$ & $0 \pm 0.00$ & $28 \pm 0.96$ \\
5 & $58 \pm 1.98$ & $4 \pm 0.80$ & $8 \pm 0.97$ \\
6 & $75 \pm 1.28$ & $13 \pm 2.33$ & $48 \pm 2.31$ \\
7 & $60 \pm 1.14$ & $10 \pm 1.34$ & $22 \pm 1.33$ \\
8 & $92 \pm 0.97$ & $26 \pm 1.85$ & $27 \pm 1.68$ \\
9 & $76 \pm 2.15$ & $19 \pm 1.66$ & $9 \pm 1.36$ \\
10 & $60 \pm 1.26$ & $22 \pm 1.40$ & $52 \pm 1.25$ \\
\hline
\end{tabular}

a. Ten colonies were established from 10 pairs $(\delta$ and $\phi$ ) randomly selected from an existing $N$. lugens biotype 1 culture on TN1 in the greenhouse. Ten lst-instar nymphs were released on 30-day-old plants. Each colony was replicated eight times.

\section{Growth and Development}

In the first generation, the insects at 13 DAI exhibited low survival on resistant Mudgo and ASD7 rice varieties (Fig. 2). Survival percentage on Mudgo improved from 10 in the first to 89 in the seventh generation. Similarly, on ASD7 it improved from 24 in the first generation to 92 in the seventh generation. However, survival on TNI was similar in all the generations, varying from 85 to $99 \%$.
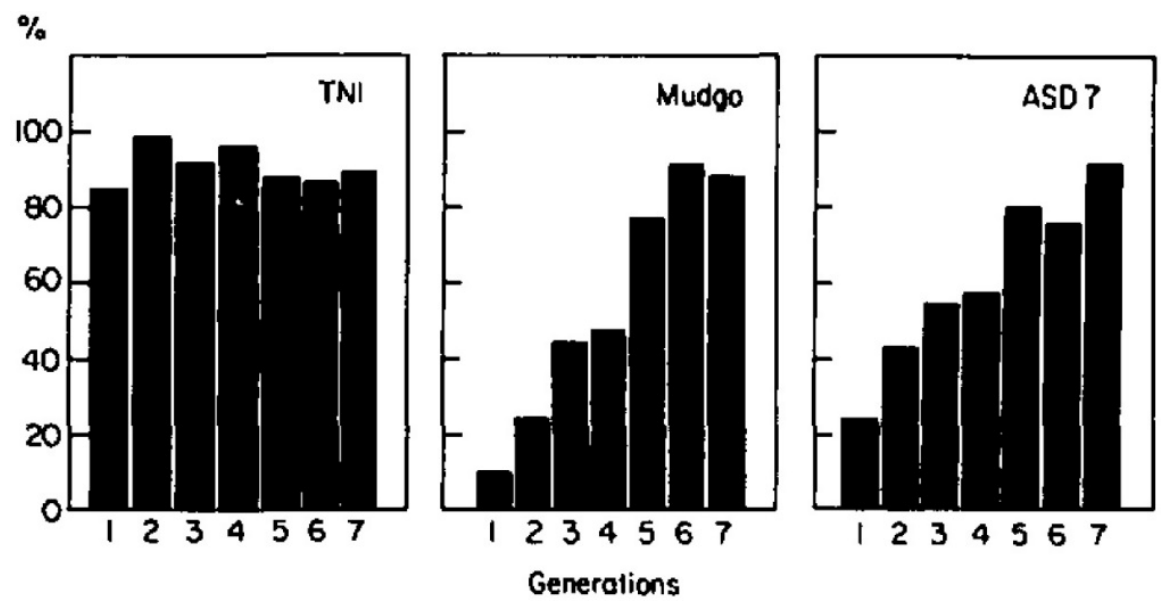

Figure 2. Percent survival of $N$. lugens biotype 1 nymphs from the first to the seventh generation on a susceptlble (TNl) and resistant (Mudgo and ASD7) rice vaneties. Each treatment consisted of 10 replications. There were 10 insects per replication on TN 1 . Because of high mortality on the resistant varieties in the first three generations there were 30 insects on Mudgo and 15 on ASD7. In the fourth generation, each treatment consisted of 10 nymphs per replicate. 
Percentage of nymphs completing development and reaching the adult stage is given in Figure 3. On Mudgo and ASD7, 47 and 37\% of the nymphs became adults in the fourth generation, respectively, but there was an increase to 88 and $92 \%$ in the seventh generation. On TN1, $98 \%$ of the nymphs became adults in the fourth generation, and this was slightly reduced to 88 to $92 \%$ in the subsequent generations.

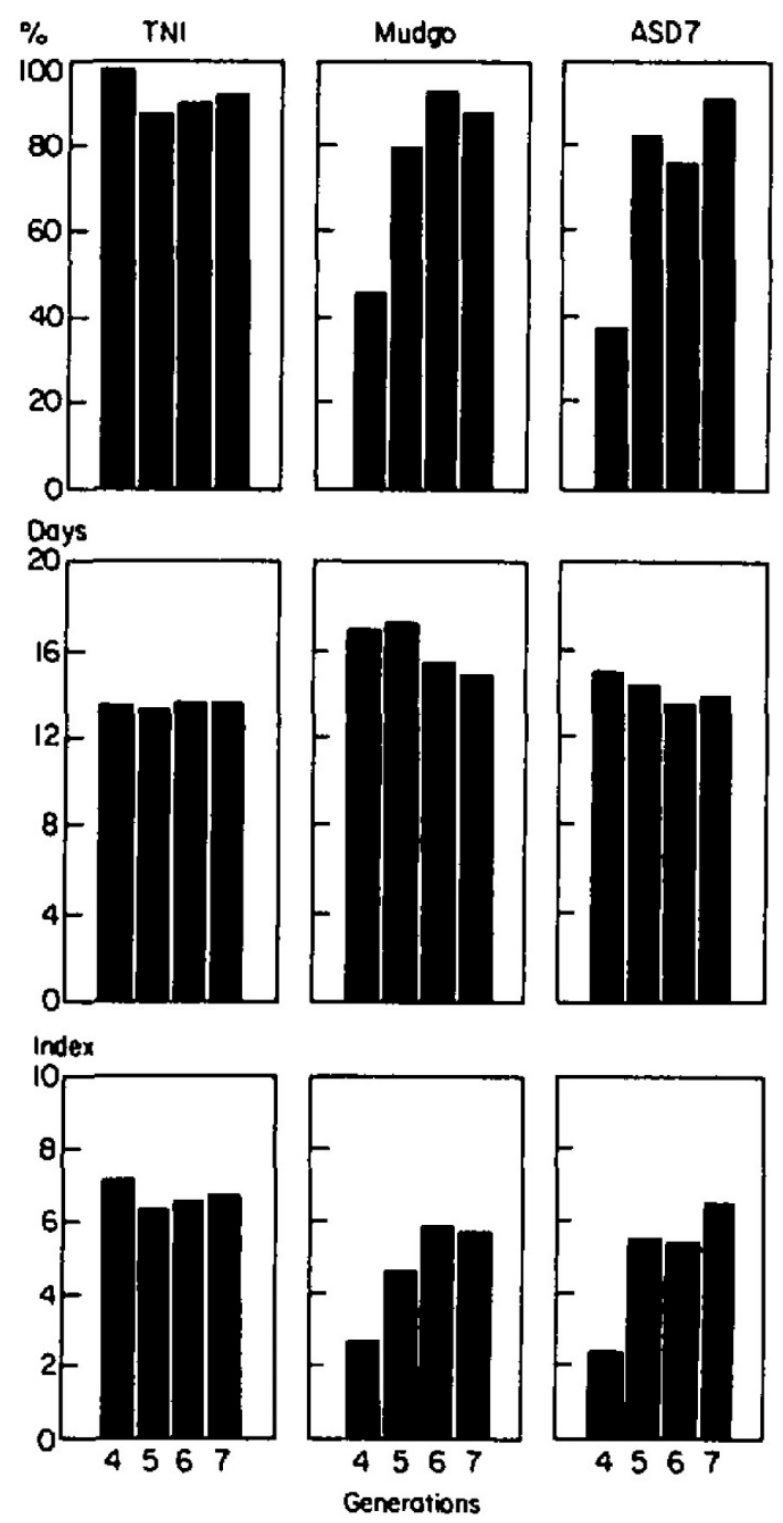

Figure 3. Percent lst-instar nymphs of $N$. lugens biotype 1 becoming adults (upper), their developmental period in days (center), and growth index (lower) from the fourth to the seventh generation when reared on susceptible (TNl) and resistant (Mudgo and ASD7) rice varieties. Treatments were replicated 10 times, each replicate consisting of 10 1st-instar nymphs. 
In the fourth generation, developmental period was longer on Mudgo (17 days) and ASD7 (15 days) as compared with TN1 (13.5 days) (Fig. 3). By the seventh generation, it was reduced to 15 days on Mudgo and 14 days on ASD7. On TN1 the developmental period was nearly constant (13.5 days) from the fourth to the seventh generations.

Because the differences in the percentages of the nymphs reaching the adult stage (Fig. 3) did not closely correspond with the period of their development, a ratio of percent nymphs completing development (percent adults formed) to the developmental period (in days) was used for comparison and is referred to as the growth index. A high growth index indicates the suitability of the plant for growth and development of insects. Because the growth index takes into account both survival and the developmental period, it was considered a more reliable parameter for comparing the suitablility of the plants for the growth of insects than either of the two criteria alone (Saxena et at. 1974). The growth index calculated from the fourth to the seventh generations on Mudgo and ASD7 showed a progressive increase, and in the seventh generation it was similar to that on TN1 (Fig. 3). There were only slight differences in the body weight $(\mathrm{mg})$ of the newly emerged adults on re-

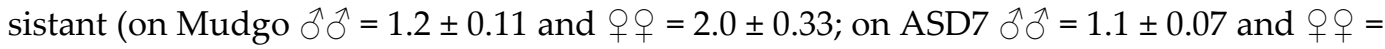
$2.1 \pm 0.76$ ) and susceptible (on TN1 $\delta \hat{\sigma}=1.2 \pm 0.20$ and 우 $=2.3 \pm 0.21$ ) varieties in the seventh generation.

\section{Adult Longevity and Fecundity}

Adults of the Mudgo selected population did not survive significantly longer on Mudgo than on ASD7 plants (Table 2). However, adults of the ASD7 selected population had longer survival on ASD7 than on Mudgo, where they died within 5 days after their confinement.

Table 2. Longevity and egg production by adults of $N$. lugens biotype 1 after being reared on one susceptible (TN1) and two resistant rice varieties (Mudgo and ASD7) for nine generations ${ }^{a}$

\begin{tabular}{|c|c|c|c|c|c|c|c|c|}
\hline \multirow{3}{*}{$\begin{array}{c}\text { Rice } \\
\text { variety }\end{array}$} & \multicolumn{4}{|c|}{ Biotype 1 reared on Mudgo } & \multicolumn{4}{|c|}{ Biotype 1 reared on ASD7 } \\
\hline & \multicolumn{2}{|c|}{$\begin{array}{c}\text { Longevity } \\
\text { (days } \pm \text { SD) }\end{array}$} & \multirow{2}{*}{$\begin{array}{c}\text { Preovi- } \\
\text { position } \\
\text { period } \\
\text { (days } \pm \\
\text { SD) }\end{array}$} & \multirow{2}{*}{$\begin{array}{l}\text { Eggs } \\
\text { pro- } \\
\text { duced } \\
\text { /female } \\
( \pm \mathrm{SD})\end{array}$} & \multicolumn{2}{|c|}{$\begin{array}{c}\text { Longevity } \\
(\text { days } \pm \text { SD) }\end{array}$} & \multirow{2}{*}{$\begin{array}{c}\text { Preovi- } \\
\text { position } \\
\text { period } \\
\text { (days } \pm \\
\text { SD) }\end{array}$} & \multirow{2}{*}{$\begin{array}{c}\text { Eggs } \\
\text { pro- } \\
\text { duced } \\
/ \text { female } \\
( \pm S D)\end{array}$} \\
\hline & Male & Female & & & Male & Female & & \\
\hline Mudgo & $16.3 \pm 2.9$ & $17.8 \pm 6.0$ & $3.5 \pm 0.5$ & $534 \pm 226$ & $3.8 \pm 1.2$ & $5.2 \pm 0.8$ & $4.3 \pm 0.4$ & $3 \pm 2$ \\
\hline ASD7 & $14.6 \pm 7.2$ & $12.3 \pm 9.6$ & $4.3 \pm 0.4$ & $279 \pm 248$ & $13.6 \pm 6.7$ & $11.7 \pm 4.3$ & $3.6 \pm 0.5$ & $222 \pm 99$ \\
\hline TN1 & $20.0 \pm 6.0$ & $18.0 \pm 7.9$ & $3.3 \pm 0.4$ & $739 \pm 372$ & $14.2 \pm 8.8$ & $15.8 \pm 1.9$ & $3.3 \pm 0.4$ & $420 \pm 139$ \\
\hline
\end{tabular}

a. Newly emerged adults were caged in pairs $(1 \hat{\sigma}, 1$ ㅇ) on 15 - to 20 -day-old plants in test tubes. Plants were changed daily. All treatments replicated four times, each replicate consisting of one pair.

Fecundity in an adult female may differ on resistant and susceptible plants in respect to the preoviposition period and number of eggs produced during its life. The preoviposition period was shortest on TN1 (Table 2). There were only marginal differences in the preoviposition period of selected populations among the three varieties, the period being slightly longer on the varieties on which the insect had not been selected. 
The population selected on Mudgo had a higher fecundity rate on Mudgo and TN1 as compared with ASD7, but due to high variation the difference was not significant. However, the ASD7 selected population laid significantly more eggs on ASD7 and TN1 as compared with Mudgo, on which only three eggs were laid.

\section{Seedling Bulk Test and Population Growth}

The resistant reaction of Mudgo and ASD7 to the parent population of biotype 1 was also evident in the third and fifth generations of the Mudgo and ASD7 selected populations, when tested by the seedling bulk test method (Table 3). But in the eighth generation, Mudgo and the ASD7 selected biotype 1 population also killed, in addition to TN1, plants of the respective varieties on which they were reared, i.e., Mudgo and ASD7. ASD7 plants showed a resistant reaction to the Mudgo population and Mudgo plants to the ASD7 population in the eighth-generation test. These reactions were further confirmed in the 10thand 13th-generation tests.

Table 3. Seedling bulk tests for virulence of biotype $1 \mathrm{~N}$. lugens populations selected on Mudgo and ASD7

\begin{tabular}{lcccccccc}
\hline & \multicolumn{2}{c}{ Reaction $^{\mathrm{b}}$ to Mudgo colony of: } & & \multicolumn{3}{c}{ Reaction $^{\mathrm{b}}$ to ASD7 colony of: } \\
\cline { 2 - 4 } \cline { 6 - 8 } Insect population & & $\mathrm{TN} 1$ & Mudgo & ASD7 & & $\mathrm{TN}$ 1 & Mudgo & ASD7 \\
\hline Parent population & $\mathrm{S}$ & $\mathrm{R}$ & $\mathrm{R}$ & & $\mathrm{S}$ & $\mathrm{R}$ & $\mathrm{R}$ \\
3rd generation & $\mathrm{S}$ & $\mathrm{R}$ & $\mathrm{R}$ & & $\mathrm{S}$ & $\mathrm{R}$ & $\mathrm{R}$ \\
5th generation & $\mathrm{S}$ & $\mathrm{R}$ & $\mathrm{R}$ & & $\mathrm{S}$ & $\mathrm{R}$ & $\mathrm{R}$ \\
8th generation & $\mathrm{S}$ & $\mathrm{S}$ & $\mathrm{R}$ & & $\mathrm{S}$ & $\mathrm{R}$ & $\mathrm{S}$ \\
10th generation & $\mathrm{S}$ & $\mathrm{S}$ & $\mathrm{R}$ & & $\mathrm{S}$ & $\mathrm{R}$ & $\mathrm{S}$ \\
13th generation & $\mathrm{S}$ & $\mathrm{S}$ & $\mathrm{R}$ & & $\mathrm{S}$ & $\mathrm{R}$ & $\mathrm{S}$ \\
\hline
\end{tabular}

a. Based on three replications, except in 3rd generation, where there was one replication. Ten 1st- and 2ndinstar nymphs were placed on 7-day-old seedlings.

b. Based on the standard evaluation system (Pathak and Saxena 1980).

Results of population growthand plant damage studies of the 13th generation of the Mudgo selected population indicated that a damage grade of 9 was obtained on Mudgo and TN1, and one of 5.8 was obtained on ASD7 within 40 days after infestation (Table 4). Similarly, a grade of 9 was recorded on ASD7 and TN1 within 34 days after infestation of the ASD7 selected population, but Mudgo plants did not show any damage and were graded as 1 even after 40 days. 
Table 4. Plant damage ${ }^{a}$ of three rice varieties by $N$. lugens populations selected for 13 generations on Mudgo and ASD7

\begin{tabular}{|c|c|c|c|c|}
\hline \multirow[b]{3}{*}{ Rice variety } & \multicolumn{4}{|c|}{ Population selected on: } \\
\hline & \multicolumn{2}{|c|}{ Mudgo } & \multicolumn{2}{|r|}{ ASD7 } \\
\hline & Damage grade ${ }^{b}$ & Days after infestation ${ }^{c}$ & Damage grade ${ }^{b}$ & Days after infestation ${ }^{c}$ \\
\hline Mudgo & 9.0 & 37 & 1.0 & 40 \\
\hline ASD7 & 5.8 & 40 & 9.0 & 34 \\
\hline TNl & 9.0 & 33 & 9.0 & 32 \\
\hline \multicolumn{5}{|c|}{$\begin{array}{l}\text { a. Two pairs of newly emerged adults were caged on 30-day-old potted plants; three hills per pot; average of } \\
\text { five replications. } \\
\text { b. Based on a scale of } 0 \text { to 9: } 0-3=\text { resistant; } 4-6=\text { intermediate; and } 7-9=\text { susceptible (Pathak and Saxena } \\
\text { 1980). }\end{array}$} \\
\hline
\end{tabular}

\section{Discussion}

The present study showed the existence of great potential in N. lugens populations for adaptation to a previously resistant rice variety. By placing N. lugens biotype 1 on Mudgo and ASD7 (both are resistant to biotype 1) a population was selected which was adapted to these varieties. The selected populations on Mudgo and ASD7 were similar in their virulence to existing populations of biotype 2 (virulent to varieties with the Bph 1 gene) and biotype 3 (virulent to varieties with the bph 2 gene) as reported by Paguia et al. (1980). The increase in survival, shortening of the developmental period, increase in the growth index, and change in the reactions in the seedling bulk test indicated very clearly that the selection process was in progress, and variants from the population which could not adapt to these resistant varieties did not survive.

Progressive increase in the adaptability of the N. lugens populations to the resistant varieties suggested that the biochemical barrier of the resistant varieties was bypassed by the selected population and that the resistant varieties became acceptable hosts (Hsiao 1978). Although the ability for such alterations in feeding habits has been suggested to be generally limited among monophagous and oligophagous insects with restricted feeding habits (Schoonhoven and Jermy 1977), N. lugens adapted readily.

Identification of host races or biotypes has strengthened the evolutionary concept of resistance in insects (Bush 1975). The present study provides information on the processes involved in $N$. lugens biotype selection. The rapid adaptation of this insect provides additional evidence to that cited by Smith (1941) that racial segregation does not require a quasigeological period of time but can occur within relatively few generations. In the present situation in the Philippines where the Bph 1 gene-adapted population (biotype 2) has become predominant after growing IR26 (Bph 1 gene) for 2 to 3 years, it has yet to be determined whether the presently grown bph 2 gene varieties (such as IR36, which occupies $80 \%$ of the rice area) will cause a shift to a population (biotype 3 ) adapted to it. Because it was possible to select a biotype virulent to the variety having the bph gene in the laboratory, similar selection might also occur in the field. IR36, however, has been grown in the 
field for years without any evidence of biotype selection occurring, and so far attempts to select a biotype on it in the laboratory have failed. The delay in the occurrence of biotype 3 may be due to the presence of minor genes in IR36 which provide field resistance.

The present study presents a technique for selecting $N$. lugens biotypes in the laboratory so as to improve the ability to predict the stability of a variety's resistance in the field. As reported by Gould (1978), patterns of variation and adaptation as herein reported for $N$. lugens are governed by population size, mobility, and whether the genetic inheritance of mechanisms responsible for the differences in adaptability are polygenic or monogenic. Experiments on crossing biotypes 1,2, and 3 at the IRRI indicated the inheritance of virulence, as based on feeding studies, to be polygenic in nature (Claridge 1979). Studies as reported here and by Claridge and Den Hollander (1980) lead to a better understanding of the patterns of variation in N. lugens. By using the techniques described, elite breeding lines should be evaluated for stability of resistance before release.

\section{Note}

1. Homoptera: Delphacidae

\section{References Cited}

Anonymous. 1976. Annual report for 1975. International Rice Research Institute, Los Baños, Philippines. $479 \mathrm{pp}$.

Bush, G. L. 1969. Sympatric host race formation and speciation in frugivorous flies of the genus Rhagolelis (Diptera, Tephritidae). Evolution 23: 237-251.

1975. Sympatric speciation in phytophagous parasitic insects, pp. 187-206. In P. W. Price [ed.]. Evolutionary strategies of parasitic insects and mites. Plenum Press. New York.

Claridge, M. F. 1979. Biotaxonomic studies on leafhopper pests of rice. Overseas Development Agency Research Scheme R3283, Annual report 1978/79. 54 pp.

Claridge, M. F., and J. Den Hollander. 1980. The "biotypes" of the rice brown planthopper , Nilapavarta lugens. Entomol. Exp. Appl. 27: 23-30.

Dyck, V. A. and B. Thomas. 1979. The brown planthopper problem. p. 3-17. In International Rice Research Institute. The brown planthopper: threat to rice production in Asia. Los Baños, Philippines. 369 pp.

Eastop, V. F. 1973. Biotypes of aphids, pp. 40-57. In A. D. Lowe, [ed.], Perspectives in aphid biology. Entomol. Soc. N. Z., Inc. Bull. No. 2. 123 pp.

Gallun, R. L., K. J. Starks, and W. D. Guthrie, 1975. Plant resistance to insects attacking cereals. Annu. Rev. Entomol. 20: 337-357.

Gould, F. 1978. Predicting the future resistance of crop varieties to pest populations: a case study of mites and cucumbers. Environ. Entomol. 7: 622-626.

Hsiao, T. M. 1978. Host plant adaptations among geographic populations of the Colorado potato beetle. Entomol. Exp. Appl. 24: 237-247.

Kaneda, C., and R. Kisimoto. 1979. Status of varietal resistance to brown planthopper in Japan, pp. 209-218. In International Rice Research Institute, the brown planthopper: threat to rice production in Asia. Los Baños, Philippines. 369 pp. 
Khush, G. S. 1979. Genetics of and breeding for resistance to the brown planthopper, pp. 321-332. Ibid.

Paguia, P., M. D. Pathak, and E. A. Heinrichs. 1980. Honeydew excretion measurement techniques for determining differential feeding activity of biotypes of Nilaparvata lugens on rice varieties. J. Econ. Entomol. 73: 35-40.

Pathak, M. D. 1977. Defense of the rice crop against pests. Ann. N. Y. Acad. Sci. 287: 287-95.

Pathak, M. D., and R. C. Saxena. 1980. Breeding approaches in rice. p. 422-56. In F. G. Maxwell and P. R. Jennings [eds.], Breeding plants resistant to insects. John Wiley and Sons, Inc., New York. 683 pp.

Saxena, K. N., J. R. Gandhi, and R. C. Saxena. 1974. Patterns of relationships between certain leafhoppers and plants. I. Responses to plants. Entomol. Exp. Appl. 17: 303-313.

Schoonhoven, L. M., and T. Jermy. 1977. A behavioral and electrophysiological analysis of insect feeding deterrents, pp. 133-145. In N. R. McFarlane [ed.], Crop protection agents - their biological evaluation. Academic Press, Inc., New York. 638 pp.

Smith, H. S. 1941. Racial segregation in insect populations and its significance in applied entomology. J. Econ. Entomol. 34: 1-13. 